\title{
PENGARUH DISIPLIN KERJA DAN KOMUNIKASI TERHADAP KINERJA KARYAWAN PADA PERUM JASA TIRTA II DIVISI PENGELOLAAN AIR III KANTOR SEKSI PATROL KABUPATEN INDRAMAYU
}

\author{
The Effect Of Work Discipline And Communication On Employee Performance In Perum Jasa \\ Tirta Ii Water Management Division Iii Patrol Sector Office

\section{Surianti} \\ Manajemen FE Unwir \\ nochyanti@gmail.com
}

\section{ABSTRAK}

Penelitian ini bertujuan mengetahui Pengaruh Disiplin kerja dan Komunikasi terhadap Kinerja karyawan Studi Kasus di Perum Jasa Tirta II Divisi Pengelolaan Air III Kantor Seksi Patrol. Data diperoleh melalui angket terhadap 32 karyawan di Perum Jasa Tirta II Divisi Pengelolaan Air III Kantor Seksi Patrol. Kesimpulan penelitian tentang Disiplin kerja dan Komunikasi terhadap Kinerja karyawan Studi Kasus Perum Jasa Tirta II Divisi Pengelolaan Air III Kantor Seksi Patrol adalah:

Hasil analisis korelasi Disiplin kerja (X1) terhadap Kinerja karyawan (Y) adalah sebesar 0,099 membuktikan bahwa pengaruh Disiplin kerja terhadap Kinerja karyawan termasuk dalam kategori sangat rendah.

Hasil analisis korelasi Komunikasi (X2) terhadap kinerja karyawan (Y) adalah sebesar 0,297 membuktikan bahwa pengaruh Komunikasi terhadap kinerja termasuk dalam kategori rendah. Hasil analisis korelasi Disiplin kerja (X1) dan Komunikasi (X2) terhadap Kinerja karyawan (Y) secara total sebesar 0,324 hal ini membuktikan bahwa pengaruh Disiplin kerja (X1) dan Komunikasi (X2) Terhadap Kinerja karyawan (Y) termasuk dalam kategori rendah.

Untuk mengetahui seberapa besar kontribusi yang diberikan Disiplin kerja terhadap Kinerja karyawan, maka dapat diperoleh dengan menghitung koefisien determinasi. Berdasarkan perhitungan didapat bahwa Disiplin kerja terhadap Kinerja karyawan memiliki kontribusi sebesar 9,801\%. Sedangkan sisanya 90,199\% dipengaruhi oleh faktor-faktor lainnya yang tidak diteliti.

Berdasarkan perhitungan tersebut maka diketahui bahwa t hitung sebesar 2,086. Selanjutnya dibandingkan dengan harga $t$ tabel. Untuk kesalahan 5\% atau taraf kepercayaan $95 \%$ dengan uji dua pihak dengan dk (derajat kebebasan) $=47$ $2=45$ didapat $t$ tabel sebesar 2,021. Dengan demikian harga $t$ hitung $>t$ tabel yaitu 2,086 > 2,021, artinya bahwa hipotesis alternatif (Ha) diterima dan Ho ditolak. Artinya, terdapat pengaruh yang signifikan antara Komunikasi (X2) terhadap Kinerja karyawan (Y).

Untuk mengetahui apakah suatu hipotesis diterima atau ditolak maka dilakukan uji t, dengan ketentuan:

Ho; $\mathbf{r}=0$ tidak ada pengaruh antara Disiplin kerja dan Komunikasi terhadap Kinerja karyawan

$\mathrm{Ha} ; \mathbf{r} \neq \mathbf{0}$ ada pengaruh antara Disiplin kerja dan Komunikasi terhadap Kinerja karyawan

Berdasarkan perhitungan tersebut maka diketahui bahwa $t$ hitung sebesar 0,151. Selanjutnya dibandingkan dengan harga $t$ tabel. Untuk kesalahan $5 \%$ atau taraf kepercayaan $95 \%$ dengan uji dua pihak dengan dk (derajat kebebasan) $=47$ $2=45$ didapat $t$ tabel sebesar 2,021. Dengan demikian harga $t$ hitung $<t$ tabel yaitu $0,151<$ 2,021, artinya bahwa hipotesis alternatif (Ha) ditolak dan Ho diterima. Artinya, tidak terdapat pengaruh yang signifikan antara Disiplin kerja (X1) dan Komunikasi (X2) terhadap Kinerja karyawan (Y).

Kata Kunci: Disiplin Kerja, Kominikasi, Kinerja Karyawan.

\section{ABSTRACT}

his study aims to determine the Effect of Work Discipline and Communication on Employee Performance Case Study at Perum Jasa Tirta II Water Management Division III Patrol Section Office. Data was obtained through a questionnaire on 32 employees at Perum Jasa Tirta II Water Management Division III Patrol Section Office. Conclusion of research on work discipline and communication on employee performance Case Study of Perum Jasa Tirta II Division of Water Management III Patrol Section Office is:

The results of the work discipline correlation analysis (X1) on employee performance (Y) is 0.099 proving that the influence of work discipline on employee performance is included in the very low category. 
Samsul Anwar

The results of the Communication correlation analysis (X2) on employee performance (Y) is 0.297 proving that the influence of Communication on performance is included in the low category.

The results of the work discipline (X1) and Communication (X2) correlation analysis on employee performance ( $Y$ ) in total amounted to 0.324 this proves that the influence of work discipline (X1) and communication (X2) on employee performance $(\mathrm{Y})$ is included in the low category.

To find out how much contribution given by work discipline to employee performance, it can be obtained by calculating the coefficient of determination. Based on the calculations obtained that the work discipline on employee performance has a contribution of $9,801 \%$. While the remaining $\mathbf{9 0 , 1 9 9 \%}$ is influenced by other factors not examined.

Based on these calculations, it is known that $t$ count is 2.086. Furthermore, it is compared with the price of $t$ table. For a $5 \%$ error or a $95 \%$ confidence level with a two-party test with dk (degrees of freedom) $=47-2=45, t$ table is 2.021 . Thus the price of $t$ count $>t$ table is $2.086>\mathbf{2 . 0 2 1}$, meaning that the alternative hypothesis (Ha) is accepted and $\mathrm{Ho}$ is rejected. That is, there is a significant influence between Communication (X2) on employee performance (Y).

To find out whether a hypothesis is accepted or rejected, a t test is carried out, provided that:

Ho; $\mathbf{r}=\mathbf{0}$ there is no influence between work discipline and communication on employee performance

Ha; r? 0 there is an influence between work discipline and communication on employee performance

Based on these calculations, it is known that $t$ count is 0.151. Furthermore, it is compared with the price of $t$ table. For a $5 \%$ error or a $95 \%$ confidence level with a two-party test with dk (degrees of freedom) $=47-2=45, t$ table is 2.021. Thus the price of $t$ count $<$ table is $0.151<2.021$, meaning that the alternative hypothesis (Ha) is rejected and $\mathrm{Ho}$ is accepted. That is, there is no significant influence between work discipline (X1) and communication (X2) on employee performance (Y)..

Key Words: Work Discipline, Communication, Employee Performance.

\section{PENDAHULUAN}

Komponen yang sangat penting dalam perusahaan adalah tenaga kerja dimana tenaga kerja merupakan salah satu faktor penentu dalam keberhasilan suatu organisasi dalam perkembangan perusahaan dan pencapaian tujuan perusahaan.

Untuk mencapai keberhasilan perusahaan dibutuhkan organisasi yang berkualitas dalam pengelolaan sumber daya manusia seperti pegawai yang memiliki pengetahuan yang baik, keterampilan dalam bekerja, serta sikap disiplin kerja yang tinggi dalam menyelesaikan setiap tugas dan tanggung jawabnya.

Kedisiplinan kerja dapat berdampak pada tugas yang dilaksanakan karyawan yang berpengaruh terhadap perusahaan. Untuk itu perusahaan perlu mengawasi setiap tindakan dan perilaku yang dilakukan oleh karyawan saat bekerja. Atasan pun sebaiknya dapat bersikap berani dan tegas dalam tindakan kedisiplinan karyawan dan melaksanakan aturan yang ada di perusahaan. Dengan adanya keteladanan pimpinan maka pimpinan harus menjadi contoh dan panutan bagi karyawan karena keteladanan pimpinan sangat berperan dalam menentukan kedisiplinan karyawan. Setiap karyawan memiliki sifat yang berbeda, begitu juga dalam hal mengikuti peraturan. Walaupun para atasan sudah ketat dalam mengawasinya, jika karyawan itu sendiri tidak memiliki kesadaran akan disiplin kerja yang diterapkan maka akan terus terjadi pelanggaran yang berdampak pada hasil kerja.

Penerapan disiplin kerja dalam sebuah organisasi mengandung konsekuensi yaitu 
Surianti

penegakan aturan. Bagi yang melanggar aturan yang ada memperoleh sanksi hukuman. Sanksi hukuman berperan penting dalam memelihara kedisiplinan karyawan.

Selain disiplin kerja, komunikasi yang efektif juga diperlukan untuk menghasilkan kinerja yang diinginkan perusahaan, komunikasi merupakan aktivitas dasar manusia. Dengan berkomunikasi, manusia dapat saling berhubungan satu sama lain baik dalam kehidupan sehari-hari di tempat kerja, dan lingkungan masyarakat. Pentingnya peran komunikasi bagi manusia tidak dapat dipungkiri, begitu juga halnya bagi suatu organisasi atau perusahaan.

Komunikasi mempunyai peranan yang penting di dalam suatu organisasi atau perusahaan. Dengan adanya komunikasi yang baik, suatu kegiatan perusahaan dapat berjalan dengan lancar dan begitupun sebaliknya, kurang atau tidak adanya komunikasi akan berakibat buruk bagi perusahaan. Komunikasi dalam organisasi berfungsi untuk memberikan informasi kepada seluruh anggota organisasi. Komunikasi yang efektif adalah penting bagi semua organisasi. Oleh karena itu, para pimpinan organisasi perlu memahami dan menyempurnakan kemampuan mereka.

Dengan terciptanya disiplin kerja dan komunikasi yang baik maka kinerja para karyawan juga akan meningkat sehingga tujuan perusahaan dapat tercapai. Setiap perusahaan selalu mengharapkan karyawannya bekerja dengan baik, karena dengan memiliki karyawan yang mempunyai kinerja yang bagus akan memberikan hasil kerja yang optimal bagi perusahaan. Perusahaan seringkali menghadapi masalah mengenai sumber daya manusianya. Masalah sumber daya manusia menjadi tantangan tersendiri bagi manajemen perusahaan karena keberhasilan manajemen tergantung pada kualitas sumber daya manusianya. Apabila individu dalam perusahaan yaitu Sumber Daya Manusia-nya dapat berjalan efektif maka perusahaan akan tetap berjalan efektif. Dengan kata lain kelangsungan suatu perusahaan itu ditentukan oleh kinerja karyawannya.

Berhasil tidaknya suatu perusahaan dalam mempertahankan eksistensinya perusahaan dimulai dari manusia itu sendiri dalam mempertahankan perusahaan dalam meningkatkan efektivitas dan efesiensi secara maksimal. Dengan kata lain kinerja organisasi atau perusahaan sangat dipengaruhi dan bahkan tergantung pada kualitas dan kemampuan sumber daya yang dimilikinya.

Keberhasilan suatu perusahaan sangat dipengaruhi oleh kinerja organisasi yang tentu saja akan bersumber dari kinerja individu. Kinerja yang baik akan dipengaruhi oleh dua hal yaitu tingkat disiplin dan komunikasi baik. Tingkat kemampuan 
komunikasi seseorang akan mempengaruhi kemampuan seseorang dalam pemahaman atas jenis pekerjaan dan keterampilan dalam melakukan pekerjaannya. Begitu juga dengan halnya tingkat kedisiplinan yang tinggi yang akan memberikan dorongan terhadap kinerja pegawai

\subsection{Batasan Masalah}

Dari uraian di atas penulis memberikan batasan masalah pada penelitian ini mengenai disiplin kerja, kominikasi dan kinerja karyawan, sehingga muncul judul Pengaruh Disiplin Kerja dan Kominukasi terhadap Kinerja Karywan

\section{TINJAUAN PUSTAKA}

Penyesuaian tenaga kerja terhadap perusahaan adalah menerapkan kedisiplinan segala bentuk yang diterapkan suatu perusahaan pada karyawannya. Kedisiplinan ini untuk menerapkan ketaatan karyawan pada peraturan dan ketentuan yang berlaku pada perusahaan untuk mencapai tujuan perusahaan. Menurut Keith Davis yang dikutip oleh Anwar Prabu Mangkunegara (2013:129) bahwa "Dicipline is management action to enforce organization standards (disiplin kerja dapat diartikan sebagai pelaksanaan manajemen untuk memperteguh pedoman-pedoman organisasi.)"

Menurut Singodimedjo (dalam buku Edy Sutrisno 2014:86) berpendapat bahwa "Disiplin adalah sikap kesediaan dan kerelaan seseorang untuk mematuhi dan menaati norma-norma peraturan yang berlaku di sekitarnya."

Dan menurut Malayu Hasibuan (2012:193) mengatakan bahwa "kedisiplinan adalah kesadaran dan kesediaan seseorang mentaati semua peraturan perusahaan dan normanorma sosial yang berlaku."

Berdasarakan definisi para ahli tersebut diatas peneliti dapat mengambil kesimpulan bahwa Disiplin Kerja adalah "Kesadaran dan kesediaan seseorang untuk mematuhi dan mentaati semua peraturan perusahaan dan norma-norma sosial untuk memperteguh pedoman-pedoman organisasi".

Manusia adalah makhluk sosial yang dimana setiap ia berada selalu bersosialisasi menggunakan komunikasi. Komunikasi dalam sebuah organisasi atau perusahaan sangatlah penting, karena tanpa komunikasi yang baik organisasi atau perusahaan tidak akan bisa berjalan dengan baik.

Menurut Andri Feriyanto dan Endang Shyta Triana (2015 : 156) berpendapat bahwa "Komunikasi adalah suatu proses di mana seseorang atau beberapa orang, kelompok, organisasi, dan masyarakat menciptakan dan menggunakan informasi agar terhubung dengan lingkungan dan orang lain."

Menurut Dr. AA. Anwar Prabu Mangkunegara (2013 :145), "komunikasi dapat diartikan sebagai proses pemindahan suatu informasi, ide, pengertian dari seseorang kepada orang lain dengan harapan 
orang lain tersebut dapat menginterpretasikan sesuai dengan tujuan yang dimaksud."

Dan menurut Malayu Hasibuan (2012:181), "Komunikasi adalah suatu alat pengalihan informasi dari komunikator kepada komunikan agar antara mereka terdapat interaksi."

Dari definisi para ahli tersebut dapat disimpulkan bahwa komunikasi adalah aktifitas pengirimanan dan penerimaan informasi, ide atau berita antara dua orang atau lebih, serta terdapat interaksi antara mereka.

Kinerja karyawan adalah hasil kerja seorang karyawan selama periode tertentu dibandingkan dengan berbagai kemungkinan, misal : standar, target/ sasaran/ kriteria yang ditentukan dan disepakati bersama. Dalam hal penilaian tetap, mempertimbangkan berbagai situasi dan kondisi yang mempengaruhi kinerja.

Menurut Sedarmayanti (2014: 260),"kinerja adalah hasil karya yang dicapai oleh seseorang atau sekelompok orang dalam suatu organisasi, sesuai dengan wewenang dan tanggungjawab masing-masing, dalam rangka upaya mencapai tujuan organisasi bersangkutan secara legal, tidak melanggar hukum dan sesuai dengan moral maupun etika."

Menurut Amirullah (2015 : 222) berpendapat, "kinerja (performance) perusahaan adalah hasil dari banyak keputusan yang dibuat secara terus-menerus oleh manajemen untuk mencapai tujuan tertentu secara efektif dan efisien."

Dan menurut Dr. AA. Anwar Prabu Mangkunegara (2013:67) mengatakan, "Kinerja (prestasi kerja) adalah hasil kerja secara kualitas dan kuantitas yang dicapai oleh seorang pegawai dalam melaksanakan tugasnya sesuai dengan tanggung jawab yang diberikan kepadanya."

Dari pendapat beberapa ahli diatas bahwa kinerja adalah hasil kerja yang dicapai dan diputuskan oleh sekelompok orang dalam suatu organisasi sesuai dengan tanggung jawab masing-masing secara efektif dan efisien.

Menurut Timpe (dalam buku Amirullah 2015: 232) faktor-faktor yang mempengaruhi kinerja yaitu:

1. Kinerja baik dipengaruhi oleh dua faktor:

a. Internal (pribadi)

- Kemampuan tinggi

- Kerja keras

b. Ekternal (lingkungan)

- Pekerjaan mudah

- Nasib baik

- Bantuan dari rekan-rekan

-Pemimpin yang baik

2. Kinerja jelek dipengaruhi oleh:

a. Internal (pribadi)

- Kemampuan rendah

- Upaya sedikit

b. Eksternal (lingkungan) 
Samsul Anwar

- Pekerjaan sulit

- Nasib buruk

- Rekan-rekan kerja yang tidak produktif

- Pemimpin yang tidak simpatik.

Tinggi rendahnya kinerja seorang pegawai ditentukan oleh faktor-faktor yang mempengaruhinya, baik secara langsung ataupun tidak langsung.

Menurut Anwar Prabu Mangkunegara (2013:67), bahwa "Faktor yang mempengaruhi pencapaian kinerja adalah faktor kemampuan (ability) dan faktor motivasi (motivation)."

Sedangkan menurut Keith Davis dalam Anwar prabu Mangkunegara (2009:67) dirumuskan bahwa faktor-faktor yang dapat mempengaruhi kinerja adalah :

$\square$ Human Performance $=$ Ability + Motivation

$\square$ Motivation $=$ Attitude + Situation

$\square$ Ability = Knowledge + Skill

\section{METODOLOGI PENELITIAN}

Metode yang digunakan dalam penelitian ini adalah Metode Hipotesis Deskriptif dan Metode Hipotesis Asosiatif.

\section{Metode Hipotesis Deskriptif}

Metode Hipotesis Deskriptif menurut Sugiyono (2013:94), "Pengujian hipotesis deskriptif pada dasarnya merupakan proses pengujian generalisasi hasil penelitian yang didasarkan pada satu sampel." Kesimpulan yang dihasilkan nanti adalah apakah hipotesis yang diuji itu dapat digeneralisasikan atau tidak. Bila Ho diterima berarti dapat digeneralisasikan. Dalam pengujian ini variabel penelitiannya bersifat mandiri, oleh karena itu hipotesis penelitian tidak berbentuk perbandingan ataupun hubungan antar dua variabel atau lebih.

2. Metode Hipotesis Asosiatif

$$
\text { Menurut Sugiyono }
$$

"Hipotesis asosiatif merupakan dugaan tentang adanya hubungan antar variabel dalam populasi yang akan diuji melalui hubungan antar variabel dalam sampel yang diambil dari populasi." Untuk itu dalam langkah awal pembuktiannya, maka perlu dihitung terlebih dahulu koefisien yang ditemukan itu diuji signifikannya. Jadi menguji hipotesis asosiatif adalah menguji koefisien korelasi yang ada pada sampel untuk diberlakukan pada seluruh populasi dimana sampel diambil.

Sumber data dalam penelitian adalah Data Primer. Data primer adalah data yang diperoleh melalui penelitian lapangan dimana penelitian tersebut dilaksanakan dengan cara melakukan observasi, angket, dan wawancara. Untuk lebih jelasnya diuraikan sebagai berikut:

a. Observasi

Observasi yaitu suatu teknik pengumpulan data berdasarkan pengamatan yang menggunakan mata atau telinga secara 
langsung tanpa melalui alat bantu terstandar. Pemakaian pengumpulan data ini dimaksudkan untuk mengetahui secara menyeluruh situasi sebenarnya dari objek yang akan diteliti.

\section{b. Angket}

Angket adalah seperangkat pertanyaan atau pernyataan yang dijawab atau dilengkapi oleh responden.

c. Wawancara

Wawancara adalah sebuah dialog yang dilakukan oleh pewawancara untuk memperoleh informasi dari terwawancara.

\section{PEMBAHASAN}

Analisis Tanggapan Responden per variabel

1. Analisis tanggapan responden terhadap Disiplin Kerja.

Tabel.1

Rekapitulasi skor tanggapan responden terhadap Disiplin Kerja

\begin{tabular}{|c|c|c|c|c|c|c|c|c|c|}
\hline \multirow{2}{*}{ Indikator } & \multirow{2}{*}{ Pertanyaan } & \multicolumn{5}{|c|}{ Jawaban } & \multirow{2}{*}{ Responden } & \multirow{2}{*}{$\begin{array}{c}\text { Jumlah } \\
\text { Skor }\end{array}$} & \multirow[b]{2}{*}{$\%$} \\
\hline & & $\mathbf{A}$ & B & C & D & $\mathbf{E}$ & & & \\
\hline \multirow[b]{2}{*}{1} & Item 1 & 85 & 96 & 18 & 0 & 0 & 47 & 199 & $52,92 \%$ \\
\hline & Item 2 & 75 & 104 & 18 & 0 & 0 & 47 & 197 & $52,39 \%$ \\
\hline \multirow[b]{2}{*}{2} & Item 3 & 105 & 104 & 0 & 0 & 0 & 47 & 209 & $55,58 \%$ \\
\hline & Item 4 & 124 & 84 & 3 & 0 & 0 & 47 & 212 & $56,38 \%$ \\
\hline \multirow[b]{2}{*}{3} & Item 5 & 105 & 92 & 9 & 0 & 0 & 47 & 206 & $54,78 \%$ \\
\hline & Item 6 & 95 & 104 & 6 & 0 & 0 & 47 & 205 & $54,52 \%$ \\
\hline \multirow[b]{2}{*}{4} & Item 7 & 70 & 120 & 9 & 0 & 0 & 47 & 199 & $52,92 \%$ \\
\hline & Item 8 & 105 & 88 & 12 & 0 & 0 & 47 & 205 & $54,52 \%$ \\
\hline \multicolumn{2}{|c|}{ JUMLAH } & 764 & 792 & 75 & 0 & 0 & 47 & 1632 & 54,50 \\
\hline
\end{tabular}

Berdasarkan data rekapitulasi tanggapan responden terhadap Disiplin Kerja diatas, responden menanggapi kuesioner "Disiplin Kerja” dengan jumlah skor 1632 atau $1632 / 1880 \times 100 \%=75,53 \%$ artinya responden menanggapi dengan klasifikasi "Baik".
2. Analisis tanggapan responden terhadap Komunikasi.

Tabel.2

Rekapitulasi skor tanggapan responden terhadap

Komunikasi

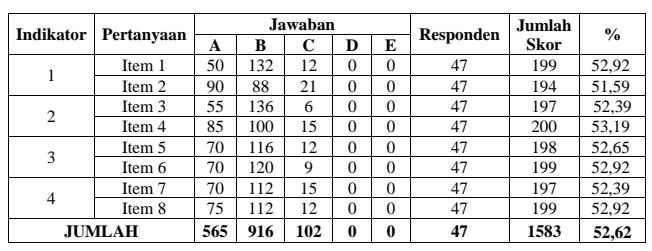

Berdasarkan data rekapitulasi tanggapan responden terhadap Komunikasi diatas, responden menanggapi kuesioner "Komunikasi” dengan jumlah skor 1583 atau $1583 / 1880 \times 100 \%=84,20 \%$ artinya responden menanggapi dengan klasifikasi "Sangat Baik".

3. Analisis tanggapan responden terhadap Kinerja Karyawan.

\section{Tabel.3}

Rekapitulasi skor tanggapan responden terhadap Kinerja Karyawan

\begin{tabular}{|c|c|c|c|c|c|c|c|c|c|}
\hline Indikator & Pertanyaan & \multicolumn{5}{|c|}{ Jawaban } & Responden & $\begin{array}{c}\text { Jumlah } \\
\text { Skor }\end{array}$ & $\%$ \\
\hline \multirow[b]{2}{*}{1} & Item 1 & 125 & 80 & 6 & 0 & 0 & 47 & 211 & 56,11 \\
\hline & Item 2 & 140 & 52 & 18 & 0 & 0 & 47 & 210 & 55,81 \\
\hline \multirow{2}{*}{2} & Item 3 & 65 & 128 & 6 & 0 & 0 & 47 & 199 & 52,92 \\
\hline & Item 4 & 105 & 96 & 6 & 0 & 0 & 47 & 207 & 55,05 \\
\hline \multirow[b]{2}{*}{3} & Item 5 & 65 & 120 & 12 & 0 & 0 & 47 & 197 & 52,39 \\
\hline & Item 6 & 95 & 100 & 9 & 0 & 0 & 47 & 204 & 54,25 \\
\hline \multirow{2}{*}{4} & Item 7 & 80 & 116 & 6 & 0 & 0 & 47 & 202 & 53,72 \\
\hline & Item 8 & 85 & 104 & 12 & 0 & 0 & 47 & 201 & 53,45 \\
\hline \multicolumn{2}{|c|}{ JUMLAH } & 760 & 796 & 75 & 0 & 0 & 47 & 1631 & 54,21 \\
\hline
\end{tabular}

Berdasarkan data rekapitulasi tanggapan responden terhadap Kinerja Karyawan diatas, responden menanggapi kuesioner "Kinerja Karyawan” dengan jumlah skor 1631 atau $1631 / 1880 \times 100 \%=75,26 \%$ artinya responden menanggapi dengan klasifikasi "Baik".

Analisis Regresi 
1. Analisis Regresi Disiplin Kerja (X1) terhadap Kinerja karyawan (Y)

Persamaan regresi dua prediktor dapat dicari nilai konstan (a) dan koefisien regresi (b) dari variabel X1 terhadap Y, sebagai berikut :

$$
\begin{aligned}
a & =\frac{\left(\sum y\right)\left(\sum X 1^{2}\right)-\left(\sum \mathrm{X} 1\right)\left(\sum \mathrm{X} 1 \mathrm{Y}\right)}{\mathrm{n}\left(\sum \mathrm{X} 1^{2}\right)-\left(\sum \mathrm{X} 1\right)^{2}} \\
& =\frac{(1631)(2663424)-(1632)(2661792)}{47(2663424)-(1632)^{2}} \\
& =\mathbf{2 2 , 5 1} \\
b_{1} & =\frac{\mathrm{n}\left(\sum X 2 y\right)-\left(\sum X 2\right)\left(\sum y\right)}{\mathrm{n}\left(\sum X 2^{2}\right)-\left(\sum X 2\right)^{2}} \\
b_{1} & =\frac{47(2581873)-(1583)(1631)}{47(2505889)-(1583)^{2}} \\
& =\mathbf{0 , 9 7 0}
\end{aligned}
$$

Dari hasil diatas, maka didapat persamaan regresi sederhana dari variabel X1 terhadap $\mathrm{Y}$ sebagai berikut:

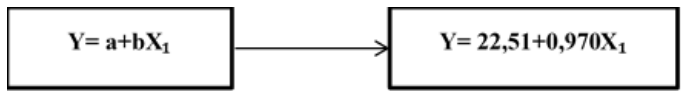

Berdasarkan persamaan diatas dapat dilihat bahwa setiap peningkatan yang terjadi pada variabel disiplin kerja (X1) menyebabkan peningkatan pula variabel Kinerja karyawan (Y).

4.

\section{KESIMPULAN}

Berdasrkan hasil pengujian dari pembahasan tentang Pengaruh Pertumbuhan Ekonomi dan BI rate Terhadap Investasi Asing Langsung di Indonesia tahun 20102017 maka diperoleh kesimpulan sebagai berikut:

1.Pertumbuhan Ekonomi selama kurun waktu penelitian berpengaruh signifikan terhadap Investasi Asing Langsung. Karena semakin tinggi tingkat pertumbuhan ekonomi di suatu negara maka semakin tinggi pula minat investor asing untuk menanamkan modalnya, sehingga investor akan memperoleh return yang diharapkan.

2.BI Rate selama kurun waktu penelitian tidak berpengaruh signifikan terhadap Investasi Asing langsung. Jadi jika BI rate Mengalami kenaikan maka Investor asing akan semakin kecil untuk menanamkan modalnay di indonesia, karena Investor tidak akan mendapatkan return yang diharapkan.

\section{DAFTAR PUSTAKA}

Abdune, J. (2013). Pengaruh domestic product, nilai tukar, suku bunga, dan inflasi terhadap penanaman modal asing di indonesia. Jurnal Airlangga university.

Azam, M. (2008). Determinants of foreign Direct Invesment in india, indonesia, pakistan. A Quantitative approach.

Baskara, Y. (2017). Pengaruh Faktor Fundamental Makro Ekonomi terhadap Keputusan Investasi Saham Asing di Indonesia tahun 2007-2014. Jurnal Administrasi Bisnis, Vol 47 No.1.

Dewi, P. K. (2015). Pengaruh pertumbuhan ekonomi, suku bunga dan pajak terhadap investasi asing langsung. E- 
Surianti

jurnal Manajemen Unud, Vol 4 No 4, 866-878.

Dewi, S. (2013). The Determinant of Foreign Direct Invesment And Their Impact on Growth: Panel Data Analysis for AMU Countries. Journal Internasional Journal of Innovation and Applied Studies, 300-313.

Eliza, M. (2013). Analisis pengaruh Makro Ekonomi terhadap Investasi Asing Langsung di Indonesia. Jurnal Malang. Fadilah, M. A. (2017). Analisis Produk Domestik Bruto, Suku bunga BI rate dan Inflasi terhadap Investasi Asing Langsung Tahun 2006-2015. Jurnal Jom Vekom, Vol 4 No.1.

Fahmi, I. (2011). Teori Portofolio dan Analisis Investasi. Bandung: Alfabeta.

G. Jayachandra. (2010). A causal Relationship between Trade, Foreign Direct Invesment and Eonomic Growth for India. Journal Internasional Research of Finance and Economic.

Ginting. (2008). Pembangunan manusis di indonesia dan faktor-faktor yang mempengaruhinya. jurnal perencanaan \& pengembangan wilayah, Vol 4 No 1 , 113-122.

Insah, B. (2013, April). Foreign Direct invesment Inflows and Economic in Ghana. journal internasional of rconomic practices and theories, Vol 3 No 2.
Leitao, N. C. (2010). Foreign Direct Invesment: The Canadian Experience Internasional. Journal Internasional of Economics and Finance, Vol 2 No 4.

Malik, A. (2017, Januari). Pengaruh utang luar negeri dan penanaman modal asing terhadap pertumbuhan ekonomi. Jurnal akuntansi, Vol 3 No 2.

Melinda, T. (2016). Pengaruh Pertumbungan Ekonomi, Bi rate dan Inflasi terhadap Investasi Asing Langsung di Indonesia. Jurnal Pendidikan Ekonomi, 4 No 3.

Rizalatul Isa, Ronny Malavia Mardani, \& Afi Rahmad Slamet. (2016). Pengaruh Tingkat Suku Bunga Deposito Bank Konvensional, Bagi Hasil, Likuiditas, PDB, terhadap Jumlah Penghimpunan Dana Pihak Ketiga Deposito Mudaharabah Bank Umum Syari'ah yang terdaftar di BI periode 20132016. Jurnal Riset Manangemen.

Rizky, R. L. (2016, Maret). Pengaruh penanaman modal asing, penanaman modal dalam negeri terhadap pertumbuhan ekonomi. jurnal JESP, Vol 8 No 1.

Salim. (2008). Hukum Investasi di Indonesia. Jakarta: Grafindo.

Sarwedi. (2002). Investasi Asing Langsung di Indonesia dan Faktor yang mempengaruhinya. Jurnal Akuntansi dan Keuangan, 17-35. 
Samsul Anwar

Seftifany, A. T., Hidayat, R. R., \& Sulasmiyati, S. (2015, Agustus). Analisis Pengaruh Inflasi, Tingkat Suku Bunga, Nilai Tukar Rupiah dan Cadangan Devisa Terhadap Penanaman Modal Asing di Indonesia. Jurnal Administrasi Bisnis (JAB), Vol. 25 No. 2.

Shah, N. (2013). Determinant of Foreign Direct Invesment: A Studi On Banglades. Journal of Economics and Sustainable Development, Vol 4 No 18, 11-19.

Soemitro, R. (2016). Dasar-dasar Hukum Pajak dan Pajak Pendapatan 1994. Bandung: PT. Eresco.

Sondakh, T. R. (2009). Implementasi Prinsip Trasparansi dalam Praktik Penanman modal di indonesia. Malang: Bayu media.

Soumia, Z., \& Abderrezzak, B. (2013, Maret). The Determinants of Foreign
Direct Invesment and their Impact on Growth: Panel data Analysis for AMU Countries. Journal Internasional of Innovation and Applied Studies, Vol 2 No 3, 300-313.

Sugiono. (2011). Metode penelitian pendidikan (pendekatan kuantitatif, kualitatif, dan R\&D. Bandung: Alfabeta.

Sukirno. (2011; 9). Ekonomi Pembangunan. Sutrisno, S. (2008). Hukum Investasi Di Indonesia. Jakarta: Grafindo Persada. Uwubanmwen, E. (2012). The Determinant and Impact of Foreign Direct Invesment in Nigeria. International Journal of Bussines and Management, 7 No 2.

Zaenuddin, m. (2009). Analisis FaktorFaktor yang mempengaruhi PMA di Batam. Jurnal Jejak, 156-166. 